\title{
A VIRTUALIZAÇÃO DO ENSINO SUPERIOR: UMA ANÁLISE DO CONTEXTO BRASILEIRO
}

Fernanda Roda de Souza Araújo Cassundé | fernanda.roda@univasf.edu.br

Doutoranda em Administração pela Universidade Federal de Pernambuco (UFPE). Professora do Colegiado de Administração da UNIVASF, PE.

José Ricardo Costa Mendonça | jrcm@ufpe.br

Doutorado em Administração pela UFRGS e

Professor do Programa de Pós-Graduação em Administração da UFPE.

\section{Resumo}

A expansão das instituições de ensino superior (IES) brasileiras tem impulsionado a adesão das universidades à educação a distância (EaD), situação especialmente favorecida com a instalação de diversos campi nas cidades do interior do país e o avanço das tecnologias de informação e comunicação (TIC). O objetivo é responder às demandas educacionais atuais, que são decorrentes de uma nova ordem econômica mundial. O que se tem percebido é um notório avanço do uso da $\mathrm{EaD}$, tanto em instituições públicas como em particulares, representando a propagação de uma nova educação em concordância com a sociedade do conhecimento $e$ as novas tecnologias. Assim, diante desse cenário educacional brasileiro, torna-se importante entender como o avanço da EaD aconteceu, a fim de conhecer as suas perspectivas e o modo como está sendo viabilizada pelas IES.

\section{Palavras-chave}

Educação a distância. Ensino superior. Virtualização do ensino. 


\section{Virtualization in Higher Education: An Analysis of the Brazilian Context.}

\section{Abstract}

The expansion of Brazilian higher education institutions, especially with the installation of several campuses in the cities of the countryside and the advancement of information and communication technologies (ICT) has been promoting the use of distance learning by universities as a way to respond to new educational demands arising from changes in the new world economic order. What we have seen is a remarkable breakthrough in the use of distance education both in public as well as in private, representing the expansion of a new education agreement with the knowledge society and new technologies. So, before the new educational scenario in which Brazilian universities are it becomes important to know how the progress of this modality happened in the Brazilian educational scenario, in order to know the prospects of distance education and how it is being made possible by the higher education institutions.

\section{Keywords}

Distance education. Higher-education.Education virtualization.

\section{Introdução}

Uma nova época educacional está sendo vivenciada nas últimas décadas, e o paradigma emergente das tecnologias de informação e comunicação (TIC) tem provocado transformações nos costumes da sociedade moderna, reestruturando aspectos metodológicos relativos ao processo de ensino-aprendizagem (TORRES; MARRIOTT; MATOS, 2009). Uma questão fundamental está sendo enfrentada pelas universidades: encarar as questões referentes às demandas de novas concepções e modalidades de ensino. Fischer (2000) complementa essa ideia ao afirmar que a revo- lução do ensino chegou e agita as escolas brasileiras. São propostas de mudanças na graduação e pós-graduação que refletem as atuais relações da sociedade, cada vez mais demandante por ensino, das políticas nacionais indutoras de transformações institucionais e de mudanças na cultura do trabalho. De fato, os professores iniciaram sua qualificação para uma "nova ambientação sem fronteiras, que se transformou, a cada segundo, e apresentou uma valiosa oportunidade de aprendizado baseado na integração e na colaboração, independentemente do tempo e do espaço" (MARTINS, 2008, p.363).

Assim, em virtude dos inúmeros apelos socioeconômicos e tecnológicos do sistema educacional, as instituições de ensino superior (IES) têm sido motivadas a interiorizar, a dinamizar e aprimorar a forma de gerar e transmitir o conhecimento. Portanto, atendendo a uma determinação prevista na Constituição Federal de 1988, desde 2002 tem ocorrido um processo de interiorização dos cursos superiores no país. Entre 2002 e 2011, por exemplo, 235 municípios que não eram atendidos por instituições de ensino superior inauguraram campi federais. $\mathrm{O}$ número deles aumentou de 151 para 284, segundo dados do Censo da Educação Superior realizado anualmente pelo Instituto Nacional de Estudos e Pesquisas Educacionais Anísio Teixeira (INEP/MEC, 2013). Como consequência dessa expansão, as unidades de ensino superior instaladas nas cidades do interior foram estimuladas a responder ao processo de regionalização por meio da educação não presencial (RAMA, 2008; STEVENS, 2010; UMAR; DANAHER, 2010).

A educação a distância aparece, então, "como uma modalidade de educação extremamente adequada e desejável para atender às novas demandas educacionais decorrentes das mudanças na nova ordem econômica mundial" (BELLONI, 2009, p.3). Por isso a criação de centros de educação a distância tem sido um processo comum das instituições educacionais nos últimos anos, a fim de viabilizar tanto o ensino de graduação quanto o de pós-graduação no país, bem como o investimento de recursos substanciais para 
explorar os potenciais do ensino superior a distância (SCHÖNWALD, 2003).

$\mathrm{O}$ avanço da Educação a Distância $(\mathrm{EaD})$ pode ser notado nas instituições públicas e particulares (privadas), representando a expansão de uma nova educação em concordância com a sociedade do conhecimento e as novas tecnologias (RAMA, 2008; MENDONÇA et al, 2012). Dados obtidos no Instituto Nacional de Estudos e Pesquisas Educacionais Anísio Teixeira (Inep) confirmam essa tendência: em 2002, quando apareceram as primeiras ofertas de cursos nessa modalidade de ensino, as estatísticas indicam 46 cursos enquanto que, em 2011 foram oferecidos 1.044 cursos a distância em instituições de ensino superior públicas e privadas.

Além do impulso recebido em termos quantitativos de cursos ofertados (de apenas 46 cursos em 2002 para 1.044 em 2011), é necessário também considerar o avanço expressivo do número de matrículas (de 29.702 matrículas em 2002 para 990.734 em 2011), conforme os dados do Inep.

Diante desse quadro, é importante saber como ele se deu, quais são as perspectivas da $\mathrm{EaD}$ no ensino superior e como ela está sendo viabilizada. Os resultados deste trabalho poderão ser utilizados na análise de tendências da implementação atual e futura da $\mathrm{EaD}$ em contextos universitários brasileiros.

\section{Educação a Distância e suas perspecti- vas no ensino superior}

Para discutir a questão da EaD no ensino superior, é importante primeiramente reconhecer a diversidade de formas com que tem sido chamada a Educação a Distância. Danaher e Umar (2010) resgataram, na literatura internacional, ao menos seis diferentes formas: ensino aberto e a distância, ensino a distância, aprendizagem aberta, aprendizagem flexível, aprendizagem online e blended learning (tendência atual, que propicia a convergência da educação presencial e a distância em um modelo híbrido). Independentemente da nomeação, o importante é concentrar-se em duas características fundamentais e inerentes a ela, quais sejam:

1. o uso de tecnologias para estabelecer combinações variadas de comunicação (síncrona e assíncrona); e

2. alunos e professores separados um do outro, seja em parte ou na totalidade da experiência educacional.

Para o Inep/MEC (2013, p.29), Educação a Distância é uma "modalidade educacional na qual a mediação nos processos de ensino e aprendizagem ocorre com a utilização de meios e tecnologias de informação e comunicação, com estudantes e professores desenvolvendo atividades educativas em lugares ou tempos diversos". Ou seja, é um processo de ensino e aprendizagem mediado pelo uso de tecnologias cujos atores (professores e alunos) estão separados no tempo e no espaço e essas distâncias são superadas (POSTLE; TYLER, 2010; JAKOBSDÓTTIR; MCKEOWN; HOVEN, 2010).

Em termos históricos, ao ser considerado um passado recente, é possível dizer que havia resistência e preconceitos intensos com relação ao ensino a distância (PRETI, 1998). No entanto, ao se tornar uma alternativa para as exigências sociais e pedagógicas ("educação para todos") e ser motivada pela crise estrutural da Educação, a EaD passou a ocupar uma posição estratégica (UMAR; DANAHER, 2010; CARNEIRO; WROBEL, 2011).

\footnotetext{
O rompimento de distâncias físicas e a interatividade possibilitada pela EaD são importantes, assim como o aprendizado orientado a distância pode ser bem-sucedido e é muitas vezes a única opção de muitos estudantes (POSSOLLI; ZAINKO, 2011, p.222).
}

Segundo Moore e Kearsley (2011), desde 1840 que, de algum modo, tem sido adotado o ensino na modalidade em questão. Inicialmente o correio era o meio utilizado para entregar materiais de estudo. $\mathrm{O}$ objetivo era integrar estudantes que, de outro modo, 
não poderiam ter acesso e se beneficiar do conteúdo. Mas foi somente com a Segunda Grande Guerra que se deu a aceleração do desenvolvimento do processo da EaD, a partir dos programas de treinamento do exército (NUNES, 2009). Para os autores, a história da Educação a Distância pode ser dividida em cinco gerações: $1^{\mathrm{a}}$ Correspondência; $2^{\mathrm{a}}$ Transmissão por rádio e televisão; $3^{\mathrm{a}}$ Universidades Abertas; $4^{\mathrm{a}}$ Teleconferência e $5^{\text {a }}$ Internet/Web. Nunes (2009, p. 2), por sua vez, afirma que os primeiros modelos da geração de ensino a distância se "desenvolveram em muitos lugares, no entanto de forma muito exitosa na Inglaterra", durante a década de 70 .

Desafios relacionados à logística, suporte de tutoria e produção de material, entre outros, têm sido superados com a elaboração de programas de Educação a Distância (RIBEIRO; TIMM; ZARO, 2007). Dentre as relevâncias, destaca-se a adequação cultural e ambiental, principalmente para a capacitação de colaboradores nas organizações. Ressalta-se ainda que a utilização dessa modalidade em treinamentos gera um aumento de interesse nos colaboradores por tal processo, além do fato de abranger um grande número de pessoas ao mesmo tempo e em diferentes locais. Com aprendizado disponível a qualquer momento, um curso de $\mathrm{EaD}$ online tem como principal benefício a redução de custo e a flexibilidade de horários para o aluno. Ademais, o diploma de uma pós-graduação a distância em nada difere de uma na modalidade presencial (BRASIL, 2013).

No entanto, muitas questões, segundo Ribeiro, Timm e Zaro (2007, p.4), "têm sido resolvidas com base na experiência pessoal dos gestores da $\mathrm{EaD}$, sem que alguma metodologia científica tenha sido empregada para auxiliar nesse sentido". Oliveira, Santos e Kalatzis (2007, p. 2) advertem ainda que, "tradicionalmente, a fase de planejamento é elaborada sem levar em conta o outro lado, o usuário do sistema [...], as formas de aprendizagem do usuário [...], a forma de processar informações, de perceber, pensar e resolver problemas".

Barbosa e Rezende (2006) comentam que dentre os problemas enfrentados pelos tutores estão: a dificuldade de compreender a ideia de uma pedagogia construtivista; a dificuldade no manuseio das tecnologias (o que demandaria o desenvolvimento de competências eletrônicas por parte dos docentes); ambiente virtual de aprendizagem inadequado; a dificuldade para realizar atividades em função da falta de tempo; e, ainda, segundo Wrobel et al (2010), a carência de um modelo predefinido a seguir para suprir a falta de experiência dos próprios tutores.

\begin{abstract}
Muitas vezes os projetos são inviabilizados ainda na fase de planejamento, tornando-os insustentáveis. Um dos pontos que bem merece ser destacado é a ocorrência de erros na implementação dos projetos, que muitas vezes resulta no não cumprimento das metas estabelecidas. A eficiência no planejamento dos projetos propicia a tomada de decisões mais eficazes, diminui o improviso e potencializa a equipe envolvida (OLIVEIRA; SANTOS; KALATZIS, 2007, p. 2).
\end{abstract}

Ou seja, não se trata tão somente de uma "infraestrutura tecnológica, declaração de princípios pedagógicos e de um local físico devidamente identificado", como salientam Ribeiro, Timm e Zaro (2007, p.3), mas também de desenvolvimento da Educação a Distância, com critérios de planejamento e gestão, bem como instrumentos para acompanhar e coordenar todas as fases.

Nesse sentido, Souza, Sartori e Roesler (2008, p.337) explicitam proposições e princípios que poderiam contribuir no processo de legitimação e aprimoramento da EaD:

a) Inserir tópicos voltados para a atuação docente em diversos contextos;

b) Expandir as pesquisas científicas sobre a $\mathrm{EaD}$;

c) Revisar o processo de formação continuada para os docentes envolvidos com a $\mathrm{EaD}$, preferencialmente os que tenham a própria prática $e$ outras experiências como objeto de análise e de redimensionamento;

d) Fortalecer o projeto político-pedagógico que norteia os projetos e iniciativas de $\mathrm{EaD}$ com intensa participação dos professores; 
e) Formar profissionais capacitados no uso crítico das TIC em processos educacionais; $e$

f) Fortalecer e difundir práticas docentes que envolvam as TIC.

\section{A modalidade de Educação a Distância nas IES brasileiras}

No entendimento de Possolli e Zainko (2011, p. 211), para assimilar o desenvolvimento da Educação a Distância no âmbito das instituições de ensino superior brasileiras é preciso traçar um paralelo com o ensino presencial nas IES "para então compreender o panorama da Educação Superior no país em que a EaD se insere", pois a cultura do ensino presencial ainda permeia a $\mathrm{EaD}$, existindo diversos estereótipos da concepção tradicional de ensino (SOUZA; SARTORI; ROESLER, 2008). Possolli e Zainko (2011, p. 212) fizeram um estudo sobre o contexto da Educação Superior presencial no país de 1980 a 2006. As análises demonstraram a intensificação histórica da privatização das IES, especialmente após o estabelecimento da Lei de Diretrizes e Bases da Educação (LDB) em 1996. Quando comparado o crescimento das instituições públicas com o das instituições particulares de ensino superior (uma diferença de 556\%), fica clara a "forte tendência privatista e a desresponsabilização do Estado pela Educação Superior".

A EaD tem mais de 70 anos de história no país e já passou por muitas etapas. Ao longo de sua trajetória, foram realizados alguns programas específicos: os cursos promovidos via cartas, pelo Instituto Universal Brasileiro (1941); o Telecurso $2^{\circ}$ grau (1978);o Mobral (1979);a TV Escola (1996). Mas somente a partir de meados dos anos 1990, após o processo de expansão da rede privada do ensino superior e da aprovação da LDB no 9.394/96, um novo contexto surgiu como referência na inovação de políticas de expansão (especialmente para a formação de professores). Trata-se da ampliação da Educação Superior pela modalidade a distância. Anterior à LDB, o Decreto $n^{\circ} 1.917$, de maio de 1996, regulamentou a criação da Secretaria de Educação a Distância (SEED).
A partir disso, o Ministério da Educação, por meio dessa secretaria, passou a atuar como um agente promotor de inovação tecnológica nos processos de ensino-aprendizagem, fomentando a incorporação das TIC e das técnicas de Educação a Distância aos métodos didático-pedagógicos. A partir de 2002, verificou-se um amplo processo de credenciamento das instituições de ensino superior, especialmente as de natureza privada, com o propósito de oferecer cursos superiores a distância. Por sua vez, o Sistema Universidade Aberta do Brasil (UAB) foi instituído somente em 2006 provocando forte impulso para a virtualização da educação. A UAB é responsável pela regulamentação, normatização, organização e financiamento da oferta pública da EaD no Brasil, oferecendo, em 2007, mais de 61.575 polos de cursos a distância, como parte de um projeto que incorporou 50 instituições federais de ensino superior e 427 municípios e estados. Nesse mesmo ano, a UAB passou a oferecer cerca de 1.300 cursos de graduação a distância em diversas áreas do conhecimento (MARTINS, 2008; RAMA, 2008; IUB, 2011; POSSOLLI; ZAINKO, 2011; UAB, 2011; BRASIL, 2013). O fato é que, apesar de ter havido alguns momentos de estagnação, o desenvolvimento desse cenário é marcado por uma trajetória de sucessos motivados pela ausência de apoio do Estado (ALVES, 2009). No entendimento de Rama (2008), o Brasil é, dos países da América Latina, aquele que está realizando o investimento mais consistente em $\mathrm{EaD}$, desde o setor público até a flexibilização da oferta para o setor privado.

O país propiciou grande demanda por educação virtual, que, por muito tempo, foi representada pelo estímulo das políticas públicas. Entretanto, tais políticas regulamentares foram duramente criticadas pela Associação Brasileira de Educação a Distância (ABED), pois, segundo ela, o MEC aprovou apenas cerca de 130 pedidos de reconhecimento dos cursos da $\mathrm{EaD}$ dos mais de 4 mil existentes. No entanto, a partir de 2001, houve uma mudança, com a Portaria $\mathrm{n}^{\circ} 2.253$ do MEC (revogada pela Portaria n ${ }^{\circ} 4.059$, de $10 / 12 / 2004$ ), que passou a permitir que até $20 \%$ da carga horária dos cursos presenciais fossem oferecidos a distância pelas IES, significando forte expansão de modos híbridos e salas de conferências. Essa regula- 
mentação promoveu um padrão de expansão da $\mathrm{EaD}$ e a virtualização do ensino superior (RAMA, 2008).

Essa nova modalidade de ensino exigiu

do ensino superior deixar um método de domínio para apreender o novo: uma aprendizagem quase compulsória em algumas situações do cotidiano que colocam o indivíduo em contato com códigos de barras, mensagens, operações e planilhas eletrônicas que compõem a nova série de atividades e exigências de um novo saber. $\mathrm{O}$ sentimento inicial era o de obsolescência da prática profissional e das ideias que atacam todas as pessoas que se encontram inseridas, de alguma forma, nesse contexto complexo (MARTINS, 2008, p. 362).

A Universidade Federal do Mato Grosso e a Universidade Federal de Santa Catarina, por exemplo, desde o início da década de 1990 merecem destaque em iniciativas universitárias de cursos de graduação via $\mathrm{EaD}$. $\mathrm{O}$ principal objetivo dos cursos criados, à época, era a formação de novos professores e o atendimento às necessidades dos que já lecionavam na Educação Básica, mas sem formação para tal (MARTINS, 2008; SPANHOL et al, 2010). "A preferência do Estado pela implantação da EaD nas IES públicas se deu pela possibilidade de ampliação da relação custo-benefício e legalizou-se por meio do atendimento à Lei de Responsabilidade Fiscal", sugerem Possolli e Zainko (2011, p. 226). As autoras exemplificam esse tipo de iniciativa por meio da criação da Universidade Virtual Pública do Brasil (UniRede).

Sobre a UniRede, vale salientar que é a primeira universidade virtual pública brasileira. Seu lançamento ocorreu em agosto de 2000, por meio de um consórcio que reúne 68 instituições públicas de ensino superior, unidas para um trabalho em rede, baseado no uso intensivo de tecnologias de informação e comunicação - principalmente a internet. O objetivo da UniRede é democratizar o acesso à educação de qualidade, ofertando cursos a distância nos níveis de graduação, pós-graduação, extensão e formação continuada. Fazem parte da UniRede: Universidade Federal do Rio de Janeiro, Universidade Estadual de Campinas, Universidade Federal de Minas Gerais, Universidade Federal de Pernambuco e Universidade Federal da Bahia, entre outras (MENEZES; SANTOS, 2002).

O avanço da Educação a Distância é notório tanto nas instituições públicas quanto nas particulares (privadas), representando a expansão de uma nova educação em concordância com a sociedade do conhecimento $e$ as novas tecnologias (RAMA, 2008; MENDONÇA et al, 2012b). Dados obtidos no Inep e apresentados na Tabela 1 confirmam essa tendência.

Tabela 1: Cursos ofertados no país (presenciais e a distância) em instituições de ensino superior públicas e privadas entre os anos de 2000 e 2011

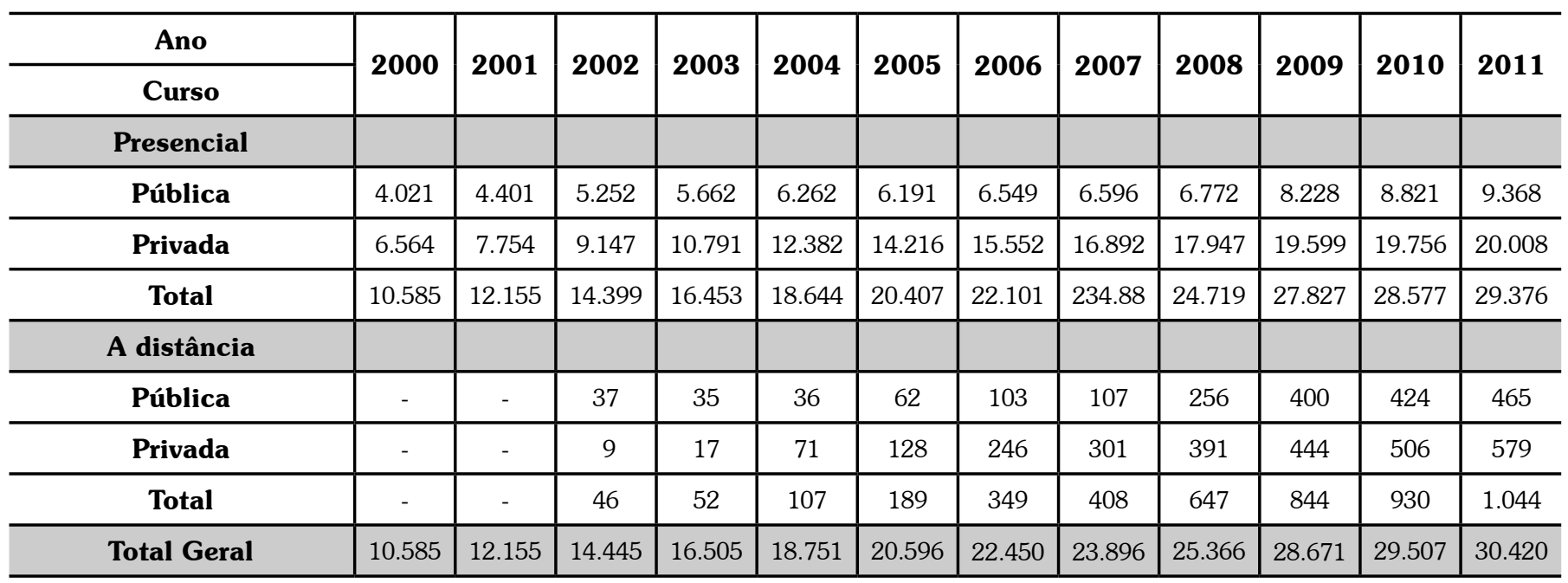

Fonte: Baseado em Mendonça et al (2012b, p.2); Inep/MEC (2013). 
Além do impulso da Educação a Distância em termos quantitativos de cursos ofertados (de apenas 46 cursos em 2002 para 1.044 em 2011), é necessário também considerar o avanço expressivo do número de matrículas nessa modalidade de ensino (de 29.702 matrículas em 2002 para 990.734 em 2011), conforme os dados obtidos no Inep e relacionados na Tabela 2.

Tabela 2: Matrículas realizadas no país em cursos presenciais e a distância (2002 -2011)

\begin{tabular}{|c|c|c|c|c|c|c|c|c|c|c|}
\hline Ano & \multirow{2}{*}{2002} & \multirow{2}{*}{2003} & \multirow{2}{*}{2004} & \multirow{2}{*}{2005} & \multirow{2}{*}{2006} & \multirow{2}{*}{2007} & \multirow{2}{*}{2008} & \multirow{2}{*}{2009} & \multirow{2}{*}{2010} & \multirow{2}{*}{2011} \\
\hline Curso & & & & & & & & & & \\
\hline \multicolumn{11}{|l|}{ Presencial } \\
\hline \multicolumn{11}{|l|}{ A distância } \\
\hline & 29.702 & 21.873 & 50.706 & 233.626 & 430.229 & 537.959 & 708.784 & 839.517 & 930.179 & 990.734 \\
\hline
\end{tabular}

Fonte: Inep/MEC (2009; 2010; 2013).

Os cursos de Pedagogia e Administração (Tabela 3) foram os que mais receberam matrículas na modalidade a distância no país, representando, no total, $61,5 \%$ de todas as matrículas realizadas na $\mathrm{EaD}$ (INEP/MEC, 2010).

Tabela 3: Os dez maiores cursos de graduação em número de matrículas por modalidade de ensino

\begin{tabular}{|c|c|c|}
\hline \multicolumn{3}{|c|}{ Graduação: presencial e a distância } \\
\hline Curso & Matrículas & $\%$ \\
\hline 1 Administração & 1.102 .579 & 18,5 \\
\hline 2 Direito & 651.730 & 10,9 \\
\hline 3 Pedagogia & 573.898 & 9,6 \\
\hline 4 Engenharia & 420.578 & 7,1 \\
\hline 5 Enfermagem & 235.804 & 4,0 \\
\hline 6 Ciências Contábeis & 235.274 & 4,0 \\
\hline 7 Comunicação Social & 221.211 & 3,7 \\
\hline 8 Letras & 194.990 & 3,3 \\
\hline 9 Educação Física & 165.848 & 2,8 \\
\hline 10 Ciências Biológicas & 152.830 & 2,6 \\
\hline Outros cursos & 1.999 .279 & 33,6 \\
\hline TOTAL (subtotal 1 + subtotal 2) & 5.954 .021 & 100 \\
\hline \multicolumn{3}{|c|}{ Presencial } \\
\hline Curso & Matrículas & $\%$ \\
\hline 1 Administração & 874.076 & 17,1 \\
\hline 2 Direito & 651.600 & 12,7 \\
\hline 3 Engenharia & 419.397 & 8,2 \\
\hline 4 Pedagogia & 287.127 & 5,6 \\
\hline 5 Enfermagem & 235.281 & 4,6 \\
\hline 6 Comunicação Social & 205.409 & 4,0 \\
\hline 7 Ciências Contábeis & 205.330 & 4,0 \\
\hline
\end{tabular}




\begin{tabular}{|c|c|c|}
\hline 8 Educação Física & 163.528 & 3,2 \\
\hline 9 Letras & 145.241 & 2,8 \\
\hline 10 Ciências Biológicas & 133.204 & 2,6 \\
\hline Outros cursos & 1.795 .703 & 35,1 \\
\hline SUBTOTAL 1 & 5.115 .896 & 100 \\
\hline \multicolumn{3}{|c|}{ Educação a distância } \\
\hline Curso & Matrículas & $\%$ \\
\hline 1 Pedagogia & 286.771 & 34,2 \\
\hline 2 Administração & 228.503 & 27,3 \\
\hline 3 Serviço Social e orientação & 68.055 & 8,1 \\
\hline 4 Letras & 49.749 & 5,9 \\
\hline 5 Ciências Contábeis & 29.944 & 3,6 \\
\hline 6 Matemática & 23.774 & 2,8 \\
\hline 7 Ciências Biológicas & 19.626 & 2,3 \\
\hline 8 História & 16.864 & 2,0 \\
\hline 9 Comunicação Social & 15.802 & 1,9 \\
\hline 10 Ciências Ambientais e Proteção Ambiental & 13.091 & 1,6 \\
\hline Outros cursos & 85.946 & 10,3 \\
\hline SUBTOTAL 2 & 838.125 & 100 \\
\hline
\end{tabular}

Fonte: Inep/MEC (2010).

Com relação à distribuição do número de matrículas de graduação na modalidade a distância, segundo os dados do Inep/MEC (2013), em consonância com as metas estabelecidas pelo Plano Nacional de Educação (PNE), o maior percentual de matrículas é referente aos cursos de licenciatura (43,3\%). Os cursos de bacharelado e de grau técnico representam $30,2 \%$ e $26,6 \%$, res- pectivamente (Tabela 4). Quando comparado ao censo da educação superior do ano anterior (2010), "no caso das matrículas a distância, o crescimento observado equivale a $12,0 \%$ para o grau tecnológico (de 235.765 para 263.970), 11,6\% para o bacharelado (de 268.173 para 299.408) e 0,8\% para a licenciatura (de 426.241 para 429.549)" (Inep/MEC, 2013, p.57).

Tabela 4: Distribuição do número de matrículas de graduação a distância, conforme grau acadêmico em 2011

\begin{tabular}{c|c|c}
\hline Grau acadêmico & Matrículas & $\mathbf{\%}$ \\
\hline Licenciaturas & 429.549 & 43,3 \\
\hline Bacharelados & 299.408 & 30,2 \\
\hline Tecnológicos & 263.970 & 26,6 \\
\hline TOTAL & 992.927 & 100 \\
\hline
\end{tabular}

Fonte: Inep/MEC (2013).

Os financiamentos estudantis, também aplicáveis à Educação a Distância, contribuem para o aumento do número de alunos nessa modalidade (Tabela 5). Esses incentivos são concedidos pelo governo (nas esferas federal, estadual ou municipal), pela pró- pria IES ou por alguma entidade financeira externa. O objetivo é oferecer aos alunos de graduação, regularmente matriculados, condições para arcarem com as mensalidades em IES não gratuitas. É possível que a mesma matrícula apresente mais de um tipo 
de financiamento, que pode ser reembolsável ou não. Nesse sentido, Sabbatini (2012, p.10) argumenta que diversos autores clamam por políticas públicas "que incentivem a ampliação e a massificação do sistema em direção às classes socioeconômicas emergentes, incluindo uma política de crédito/financiamento estudantil que contemple especificamente a EaD".

Tabela 5: Número de matrículas que possuem pelo menos um tipo de financiamento nos cursos de graduação na modalidade a distância em 2011

\begin{tabular}{c|c|c}
\hline \multirow{2}{*}{ Organização acadêmica } & \multicolumn{2}{|c}{ Modalidade de ensino a distância } \\
\cline { 2 - 3 } & Financiamento reembolsável & Financiamento não reembolsável \\
\hline Universidades & 1.894 & 73.828 \\
\hline Centros universitários & 50 & 26.297 \\
\hline Faculdades & 579 & 11.570 \\
\hline IFs e Cefets & - & - \\
\hline TOTAL & 2.523 & 111.695 \\
\hline
\end{tabular}

Fonte: Inep/MEC (2013).

No que diz respeito aos estudantes, o Censo da Educação Superior (INEP/MEC, 2013) traça um perfil a partir da moda de cada atributo considerada separadamente. $\mathrm{O}$ aluno típico que frequenta cursos de gra- duação a distância é do sexo feminino e está vinculado à licenciatura de uma instituição de ensino superior particular. A idade modal é de 30 anos, conforme os dados da Tabela 6.

Tabela 6: Perfil do vínculo discente dos cursos de graduação na modalidade a distância em 2011

\begin{tabular}{c|c}
\hline Atributos do vínculo discente de graduação & Modalidade a distância \\
\hline Sexo & Feminino \\
\hline Categoria administrativa & Particular \\
\hline Grau acadêmico & Licenciatura \\
\hline Turno & - \\
\hline Idade (matrícula) & 30 \\
\hline Idade (ingresso) & 30 \\
\hline Idade (concluinte) & 30 \\
\hline
\end{tabular}

Fonte: Inep/MEC (2013).

De modo geral, Possolli e Zainko (2011, p.217) afirmam que é preciso considerar como a $\mathrm{EaD}$ tem contribuído para a "proliferação de instituições de ensino privado e a possibilidade de essa modalidade educativa estar cumprindo o intento neoliberal do Estado mínimo, que se exime da responsabilidade pela educação".
A modernização educacional de caráter conservador implementa a Educação a Distância pavimentando o caminho de expansão do ensino privado. Por esta via, estimula empreendimentos em áreas nas quais a educação se mostra rentável: ensino superior e especializado. Em paralelo, ao descaso de políticas educacionais prosperam formas de investimento que transformam a educação em negócio. À modernização tecnológica apregoada pelas políticas oficiais adicionam-se estratégias publicitárias de supervalorização do conhecimento e da educação (BATISTA, 2002, p.21). 
Apesar de todo o aprendizado que têm experimentado outras nações, como Inglaterra, França, África do Sul, Canadá, Espanha, Portugal e Hong Kong, que aperfeiçoaram sistemas de Educação a Distância ainda na primeira metade do século XX (NEDER, 2000), convive-se com resistências à ideia de se fazer Educação Superior no Brasil pela modalidade Educação a Distância, sob o questionável argumento da falta de qualidade no ensino praticado nessa categoria. (NEDER, 2000; WROBEL et al, 2010).

\section{Considerações finais}

Este artigo apresentou uma discussão sobre a virtualização do ensino superior brasileiro a partir da inserção da modalidade Educação a Distância nas IES brasileiras.

Diante da expansão do ensino superior brasileiro e sua interiorização, promovida por políticas governamentais, as instituições de ensino superior foram estimuladas a utilizar os recursos tecnológicos e, consequentemente, adotar a $\mathrm{EaD}$ como forma de aprimorar o modo de gerar e transmitir o conhecimento. A Educação a Distância tem aparecido nesse contexto, portanto, como uma modalidade eminentemente adequada no sentido de atender às novas demandas educacionais de- correntes das alterações na nova ordem econômica mundial.

O que se percebe nesse cenário é que, apesar de os números apresentados demonstrarem que existe crescimento de cursos ofertados e do número de matrículas na modalidade a distância, as mudanças para esse modelo de ensino ainda apresentam muitas exigências. Elas implicam não somente transformar a concepção que os docentes têm do processo de ensino-aprendizagem e fazer uso dos meios tecnológicos, mas também oferecer todo um suporte institucional a cada um dos atores envolvidos, pois, caso isto não ocorra, continuaremos diante da velha abordagem (presencial), apenas apresentada com uma nova roupagem (ARRUDA, 2007). Conforme apontam Neder (2000) e Wrobel et al (2010), apesar do sucesso da EaD em outros países, no Brasil ainda existe certa resistência à ideia de fazer Educação Superior nesses moldes, pois argumenta-se que não há qualidade suficiente no ensino.

Construir a Educação Superior integrando os três pilares - ensino, pesquisa, extensão - é uma tarefa ainda mais desafiadora quando o assunto adota a modalidade a distância. O simples ato de ensinar, por exemplo, poderá perder a sua essência se não sair do papel um projeto eficiente, que possa superar as resistências e o conservadorismo adotando formas transformadoras para trabalhar o processo de ensino-aprendizagem nas universidades.

\section{Referências}

ALVES, João Roberto Moreira. A história da EaD no Brasil. In: LITTO, Frederic M.; FORMIGA, Marcos. Educação a distância: o estado da arte. São Paulo: Pearson, 2009.

ARRUDA, Heloisa Paes de Barros. Entre o presencial e o virtual: a videoconferência, sentimentos e emoções implicados. In: BEHRENS, Marilda Aparecida; ENS, Romilda Teodora; VOSGERAU, Dilmeire Sant'Anna Ramos. Discutindo a educação na dimensão da práxis. Curitiba: Champagnat, 2007.

BARBOSA, Maria de Fátima S. O.; REZENDE, Flávia. A prática dos tutores em um programa de formação pedagógica a distância: avanços e desafios.Interface, v.10, n.20, p.473-486, 2006.

BELLONI, Maria Luiza. Educação a distância. $5^{\mathrm{a} e d .}$ Campinas: Autores Associados, 2009.

BRASIL. Ministério da Educação. Disponível em:<http://portal.mec.gov.br>. Acesso em: 11 mai. 2013. 
CARNEIRO, Teresa Cristina Janes; WROBEL, Julia Schaetzle. Pesquisa em educação a distância: análise dos anais dos dois principais congressos no Brasil.VIII Congresso Brasileiro de Ensino Superior a Distância. Ouro Preto, outubro de 2011.

DANAHER, Patrick Alan; UMAR, Abdurrahman. Contemporary research on open and distance learning in teacher education. In: DANAHER, Patrick Alan; UMAR, Abdurrahman. Teacher education through open and distance learning. Vancouver: Commonwealth Learning, 2010.

FISCHER, Tânia Maria Diederichs. Organizações: seis propostas para ensino no decênio 2000/2010. In: I Encontro Nacional de Estudos Organizacionais - ENEO, 2000, Curitiba. Anais... 2000 - CD-ROM. 2000.

INSTITUTO NACIONAL DE ESTUDOS E PESQUISAS EDUCACIONAIS ANÍSIO TEIXEIRA. Censo da Educação Superior 2008 - resumo técnico. Brasília: Instituto Nacional de Estudos e Pesquisas Educacionais Anísio Teixeira, 2009.

Censo da Educação Superior 2009 - resumo técnico. Brasília: Instituto Nacional de Estudos e Pesquisas Educacionais Anísio Teixeira, 2010.

. Censo da Educação Superior 2011- resumo técnico. Brasília: Instituto Nacional de Estudos e Pesquisas Educacionais Anísio Teixeira, 2013.

IUB. Instituto Universal Brasileiro. Disponível em: <http://www.institutouniversal.com.br/> . Acesso em: 16 dez.2011.

JAKOBSDÓTTIR, Sólveig; MCKEOWN, Lindy; HOVEN, Debra. Using the new information and communication technologies for the continuing professional development of teachers through open and distance learning. In: DANAHER, Patrick Alan; UMAR, Abdurrahman. Teacher education through open and distance learning. Vancouver: Commonwealth Learning, 2010.

MARTINS, Onilza Borges. Os caminhos da EaD no Brasil. Revista Diálogo Educacional, Curitiba, v.8, n.24, p.357-371, maio/ago. 2008.

MENDONÇA, José Ricardo Costa; PAIVA, Kely César Martins; PADILHA, Maria Auxiliadora; BARBOSA, Milka Alves Correia; MARTINS, Marco Antônio Buarque. Competências eletrônicas de professores para Educação a Distância no Ensino Superior no Brasil: discussão e proposição de modelo de análise. In: Fórum da Gestão do Ensino Superior nos Países e Regiões de Língua Portuguesa, 2012, Macau, China. Anais... Macau, China: Instituto Politécnico de Macau, 2012.

MENEZES, Ebenezer Takuno de; SANTOS, Thais Helena dos. "UniRede (Universidade Virtual Pública do Brasil)" (verbete). Dicionário Interativo da Educação Brasileira. São Paulo: Midiamix, 2002. Disponível em:<http:/www.educabrasil.com.br/eb/dic/dicionario.asp?id=383>.Acesso em 11 mai./2013.

MOORE, Michael; KEARSLEY, Greg. Educação a distância: uma visão integrada. São Paulo: Cengage Learning, 2011.

MORAN, José Manuel. O que é educação a distância. 2003. Disponível em: <www.eca.usp.br/prof/moran/ dist.htm >. Acesso em: 16 dez./2011.

NEDER, Maria Lúcia Cavalli. A orientação acadêmica na educação a distância: a perspectiva de (re)significação de paradigmas educacionais. In: PRETI, Oreste (org.). Educação a distância: construindo significados. Cuiabá: NEaD/UFMT, 2000. 
NUNES, Ivônio Barros. A história da EaD no mundo. In: LITTO, Frederic M.; FORMIGA, Marcos. Educação a distância: o estado da arte. São Paulo: Pearson, 2009.

OLIVEIRA, Selma Regina Martins; SANTOS, Elaine Maria dos; KALATZIS, Adriana Casale. Suporte metodológico para aperfeiçoamento de planejamento em EaD utilizando estilos de aprendizagem, inteligências múltiplas e competências requeridas: um estudo multicasos nos cursos de Administração. In: I Encontro de Ensino e Pesquisa em Administração e Contabilidade, 2007, Recife-PE. Anais... Recife: ANPAD, 2007.

POSSOLLI, Gabriela Eyng; ZAINKO, Maria Amélia Sabbag. Políticas de expansão da Educação Superior e formação de professores na modalidade Educação a Distância. In: ENS, Romilda Teodora; BEHRENS, Marilda Aparecida. Políticas de formação do professor: caminhos e perspectivas. Curitiba: Champagnat, 2011.

POSTLE, Glen; TYLER, Mark A. Learning and teaching strategies and practices in teacher education through open and distance learning. In: DANAHER, Patrick Alan; UMAR, Abdurrahman. Teacher education through open and distance learning. Vancouver: Commonwealth Learning, 2010.

PRETI, Oreste. Educação a distância e globalização: desafios e tendências. Revista Brasileira de Estudos Pedagógicos, Brasília, v. 79, n. 191, p19-30, jan./abr. 1998.

RAMA, Claudio. Tipología de las tendencias de la virtualización de la educación superior en América Latina. Revista Diálogo Educacional, Curitiba, v.8, n.24, p.41-355, maio/ago. 2008.

RIBEIRO, Luis Otoni Meireles; TIMM, Maria Isabel; ZARO, Milton Antonio. Gestão de EaD: a importância da visão sistêmica e da estruturação dos CEaDs para a escolha de modelos adequados. CINTED-UFRGS. V. 5. n.1, jul. 2007.

SCHÖNWALD, Ingrid. Sustainable implementation of e-learning as a change process at universities. St. Gallen: Swiss Centre for Innovations in Learning, 2003.

SOUZA, Alba Regina Battisti; SARTORI, Ademilde Silveira; ROESLER, Jucimara. Mediação pedagógica na Educação a Distância: entre enunciados teóricos e práticas construídas. Revista Diálogo Educacional, Curitiba, v.8, n.24, p.327-339, maio/ago. 2008.

SABBATINI, Marcelo. Arapuca, mina de ouro ou futuro inevitável? Análise de conteúdo do discurso sobre a educação a distância $(\mathrm{EaD})$ na mídia generalista e setorial do ensino privado. XXXV Congresso Brasileiro de Ciências da Comunicação, Fortaleza-CE, 2012.

SPANHOL, Fernando José; TOSTA, Kelly Cristina Benetti Tonani; GIGLIO, Kamil; FREIRE, Patrícia de Sá. O estado da arte da educação a distância: uma meta-análise da contribuição da UFSC. 16 CIAED - Congresso Internacional ABED de Educação a Distância, Foz do Iguaçu-PR, 2010.

STEVENS, Ken. The use of media in teacher education through open and distance learning. In: DANAHER, Patrick Alan; UMAR, Abdurrahman. Teacher education through open and distance learning. Vancouver: Commonwealth Learning, 2010.

TORRES, Patrícia Lupion; MARRIOTT, Rita de Cássia Veiga; MATOS, Elizete Lúcia Moreira. Mediação pedagógica com o uso de mapas conceituais em ambiente virtual de aprendizagem. In: ENS, Romilda Teodora; BEHRENS, Marilda Aparecida; VOSGERAU, Dilmeire Sant'Anna Ramos. Trabalho do professor no espaço escolar. Curitiba: Champagnat, 2009.

UAB. Universidade Aberta do Brasil. Disponível em: <http://uab.capes.gov.br/>. Acesso em: 16dez./2011. 
UMAR, Abdurrahman; DANAHER, Patrick Alan. Setting the scene for interrogating teacher education through open and distance learning. In: DANAHER, Patrick Alan; UMAR, Abdurrahman. Teacher education through open and distance learning. Vancouver: Commonwealth Learning, 2010.

WROBEL, Julia Schaetzle; CARNEIRO, Teresa Cristina Janes; PALMA, Waneide de Sousa; AGUIAR, Lemuel Brasil. Tutoria em Educação a Distância: teoria, prática, aprendizados e desafios. Administração: Ensino e Pesquisa, Rio de Janeiro, v.11, n.3, p.331-354, jul./set./2010. 